\title{
The protective effect of Sambucus ebulus against lung toxicity induced by gamma irradiation in mice
}

\author{
Mohammad Karami ${ }^{1 *}$, Seyed Sajad Ale-Nabi ${ }^{2}$, Anahita Nosrati ${ }^{3}$, Atefeh Naimifar ${ }^{2}$ \\ ${ }^{1}$ Department of Toxicology and Pharmacology, Faculty of Pharmacy, Mazandaran University of Medical Sciences, Sari, Iran \\ ${ }^{2}$ Pharmaceutical Sciences Research Center, Hemoglobinopathy Institute, Mazandaran University of Medical Sciences, Sari, Iran \\ ${ }^{3}$ Department of Pathology, Faculty of Medicine, Mazandaran University of Medical Sciences, Sari, Iran
}

Received: Oct 26, 2014, Revised: Dec 31, 2014, Accepted: Jan 10, 2015

\begin{abstract}
The aim of present study was to investigate the potential antioxidant and lung protective activities of Sambucus ebulus (SE) against toxicity induced by gamma irradiation. Hydroalcoholic extract of SE (20, 50 and $100 \mathrm{mg} / \mathrm{kg}$ ) was studied for its lung protective activity. Phenol and flavonoid contents of SE were determined. Male C57 mice were divided into ten groups with five mice per group. Only the first and second groups (as negative control) received intraperitoneally normal saline fluid. Groups 3 to 5 received only SE extract at doses of $20 \mathrm{mg} / \mathrm{kg}, 50 \mathrm{mg} / \mathrm{kg}$ and $100 \mathrm{mg} / \mathrm{kg}$ intraperitoneally; three groups were repeatedly injected for 15 days as chronic group. Groups 6 to 8 received a single-dose of gamma irradiation just 2 hours before irradiation as acute group. The ninth and tenth groups (as positive control) received only gamma rays. Animal was exposed whole-body to 6 Gy gamma radiation. After irradiation, tissue sections of lung parenchyma were examined by light microscope for any histopathologic changes. $\mathrm{SE}$ at doses 50 and $100 \mathrm{mg} / \mathrm{kg}$ improved markedly histopathological changes induced by gamma irradiation in lung. Lung protective effect of SE could be due to attention of lipid peroxidation. Our study demonstrated that SE as a natural product has a protective effect against lung toxicity induced by gamma irradiation in animal.
\end{abstract}

Keywords: Sambucus ebulusi, gamma irradiation, histopathology changes, antioxidant, lung protective

\section{Introduction}

Herbs, which have been used for centuries in treating various illnesses, play a major role in forming the basic platform of modern medicine (1). The therapeutic effects of many traditional herbs are due to the presence of natural antioxidants, especially phenolic compounds (2). These compounds are able to scavenge reactive oxygen species (ROS) that may cause various diseases related to oxidative stress such as cancer, hypertension, and impaiment To protect humans from oxidative stress, various herbs and plants are being utilized for their potential benefits in preventing diseases related to oxidative stress. One of these herbs is Sambucus ebulus (Dwarf elder). Sambucus ebulus (SE), family of Caprifoliaceae, is extracted from the roots and leaves of Sambucus ebulus L in traditional medicine. They are frequently used for the treatment of inflammatory diseases such as inflammatory joint diseases, rheumatic pain and sore throat (3). Several pharmacological effects have been previously reported for Sambucus species, such as anti-inflammatory (4-7), antiviral (8), antibacterial (9) and radical scavenging activities $(7,10)$. Moreover, the significant inhibitory effects of the plant extracts reported on interleukins- $1 \alpha$ and $1 \beta$ and tumor necrosis factor- $\alpha$. However, the potential of wound healing of Sambucus species has not been investigated so far. Therefore, the aim of present study was to investigate the potential antioxidant and Lung protective activities of SE extract induced by gamma-radiation. A number of studies have been reported on the phytochemical composition of SE leaves. Recently, six new iridoid glycosides of the Valeriana type have been isolated from the leaves of the plant (11). In addition to the

*E-mail: toxkarami@gmail.com 
secondary metabolites, a new family of acidic type 2 (ebulitins $\alpha, \beta$ and $\gamma$ ) and basic type 1 (ebulin 1) ribosome-inactivating nontoxic protein derivatives $(12,13)$ and dimeric and mucin binding lectins and flavonoids were isolated from the matured leaves (14). However, other phytochemicals in the leaves of the plant have not been studied thoroughly. Flavonoids are used for their several therapeutic effects, such as antioxidant, anti inflammatory, antifungal, and wound healing (15, 16). Inhibition of lipid peroxidation effect by flavonoids is supposed to increase the viability of collagen fibrils by activating the DNA synthesis and preventing the cell damage (17, 18). Flavonoids are also known to promote the rapid wound healing due to their antimicrobial and astringent properties (19). Thus, wound healing effect of $S E$ might belong to the phytochemicals in the leaves, accelerating the proliferation phase of wound healing. The constituents in the volatile extract and petroleum ether, ethanol, and water extract of SE exhibited clear antioxidant activities (3).

Basically, oxygen is essential for life, but it can also be harmful to cells. This is because of reactive oxygen species (ROS), active forms of oxygen, such as hydroxyl $\left(\mathrm{OH}^{-}\right)$and superoxide $\left(\mathrm{O}_{2}^{-}\right)$radicals, hydrogen peroxide $\left(\mathrm{H}_{2} \mathrm{O}_{2}\right)$, and singlet oxygen $\left(\mathrm{IO}_{2}\right)$ which are arisen as byproducts and intermediate substances of aerobic metabolism and during oxidative stress. Similar reactions are also generated during gamma ray irradiation $(20,21)$. To the best of our knowledge, lung protective activity of SE has not been reported so far and nothing has been found about mechanism of SE activity. Thus, the aim of the present work was to determine the lung protective activity (or antioxidant activity) of SE against oxidant-induced gamma radiation and also to understand the usefulness of this plant as a foodstuff as well as a remedy in medicine. Moreover, gamma radiation was employed to evaluate SE lung protective activity and its correlation to histopathologic changes.

\section{Materials and methods}

Animals

Adult male C57 mice (6 to 8 weeks), weighing $25-30 \mathrm{~g}$ were purchased from Institute of Pasteur. They were housed individually in standard mice cages in a room on a 12- hour light- dark cycle at $22{ }^{\circ} \mathrm{C}\left(22 \pm 1{ }^{\circ} \mathrm{C}\right)$ and with $50 \pm 5 \%$ relative humidity, including food, water and libitum. The animals were adapted to the condition for 7 days prior to the beginning of the experiments (22). The experiments were performed during the day time (08:00-16:00 hours). A research proposal (No. 91-331) was prepared according to the guidelines of Committee for the Purpose of Control and Supervision of Experiments on Animals (CPCSEA).

\section{Plant}

Dried Sambucus ebulus or Dwarf elder was used for this investigation (collected at $\mathrm{km} 5$, Sari-Ghaemshahr Road), identified and confirmed in January 2012 and also authenticated by Dr. Bahman Eslami (Department of Biology, Islamic Azad University of Qhaemshahr, Iran). SE was dried at room temperature and an ethanol-water (1:1) extraction was made by using maceration method, soaking in the solvent mixture. The extract was collected after removing the solvent and lyophilized and then was suspend in phosphate buffer ( $\mathrm{pH} 7.4)$ and injected to case groups (Groups 3 to 8) intraperitoneally for protective studies (23).

\section{Determination of total phenolic and flavonoid content}

Total phenolic compound content was determined by the Folin-Ciocalteau method ( 9 , $10,11)$. The extract sample $(0.5 \mathrm{~mL}$ of different dilutions) was mixed with $2.5 \mathrm{~mL}$ of $0.2 \mathrm{~N}$ Folin-Ciocalteau reagent for $5 \mathrm{~min}$, and then 2.0 $\mathrm{ml}$ of $75 \mathrm{~g} / \mathrm{l}$ sodium carbonate were added. The absorbance of reaction was measured at $760 \mathrm{~nm}$ after $2 \mathrm{~h}$ of incubation at room temperature. Results were expressed as gallic acid equivalents. Total flavonoid was estimated according to the method of Ebrahimzadeh, MA et al $(23,24)$. Briefly, $0.5 \mathrm{~mL}$ solution of extract in methanol was mixed with $1.5 \mathrm{~mL}$ of methanol, $0.1 \mathrm{~mL}$ of $10 \% \mathrm{AlCl}_{3}, 0.1 \mathrm{~mL}$ of $1 \mathrm{M}$ potassium acetate, and $2.8 \mathrm{ml}$ of distilled water and then left at room temperature for 30 minutes. The absorbance of the reaction mixture was measured at $415 \mathrm{~nm}$ with a double beam spectrophotometer (Perkin Elmer, USA). Total flavonoid content was calculated as quercetin from a calibration curve.

\section{Gamma irradiation}

The Cobalt Teletherapy Unite was used for irradiation at Cancer Treatment Centre, Department of Radiotherapy, Martyr Rajai 
Medical College and Hospital, Babolsar (Iran) with a cobalt-60 $\gamma$ - radiations source (Teratron 780 , Canada). Mice were restrained in a well ventilated Perspex box and anaesthetized with ether. Then the whole-body was exposed to 6 Gy gamma radiation at a distance (SSD) of 77.5 $\mathrm{cm}$ from the source to deliver the dose rate of $0.85 \mathrm{~Gy} / \mathrm{min}(25)$.

\section{Experimental design}

Mice were divided into ten groups with five mice per group. Only the first and second groups (as negative control) received normal saline intraperitoneally. Groups 3 to 5 received only SE extract at doses of $20 \mathrm{mg} / \mathrm{kg}, 50 \mathrm{mg} / \mathrm{kg}$ and $100 \mathrm{mg} / \mathrm{kg}$ intraperitoneally; three groups were repeatedly injected for 15 days as chronic group. Groups 6 to 8 received a single dose of gamma irradiation just 2 hours before irradiation as acute group. Groups 9 and 10 (as positive control) received only gamma rays. Mice were exposed whole body to 6 Gy gamma radiation $(26,27)$. Following the preliminary study, the dose of $50 \mathrm{mg} / \mathrm{kg}$ was selected for the remaining of the study in order to evaluate the lung protective effect of SE (27).

\section{Biochemical determination}

Homogenate samples of gamma radiation treated groups were collected and analyzed for determination of lung Glutathione reductase (GSH) level using a commercial Kit of Zist Shimie (Tehran, Iran) and Ellman's method (28).

\section{Histological studies}

Mice were sacrificed and their lungs were removed for histopathological examination. The lungs were completely excised and any extraneous tissues were also released from them. Multiple samples were then taken from each lung (mean $3 \mathrm{~mm}$ in diameter) and placed in $10 \%$ neutral buffered formalin. After paraffin embedding, they were cut into 4-5 $\mu \mathrm{m}$ thick sections, stained with hematoxylin-eosin and observed under a light microscope (Model N 400ME, CEL-TECH Diagnostics, Hamburg, Germany), studied pathological factors in lung cellular damage, including necrosis and inflammatory cells infiltration.

\section{Statistical analysis}

Statistical analysis was performed using SPSS for Windows (Ver.10, SPSS, Inc., Chicago, USA). All values were analyzed by one-way analysis of variance (ANOVA) and expressed as mean \pm Standard error in the mean of 4 rats (S.E.M). Student-Newman-Keuls test was used to evaluate the significance of the obtained results. $\mathrm{P}<0.05$ was considered to be significant.

\section{Results}

Total phenol and flavonoid contents

Total phenol compound was determined by Folin Ciocalteu method. It was used gallic acid as reference for standard curve $\left(\mathrm{y}=0.0063 \mathrm{x}, \mathrm{r}^{2}=\right.$ $0.987)$. The total phenolic content was $118.94 \pm$ $2.78 \mathrm{mg}$ gallic acid equivalent/g of SE extract. The total flavonoid content was $58.22 \pm 1.34 \mathrm{mg}$ quercetin equivalent/g of SE extract, by reference to standard curve $(\mathrm{y}=0.0067 \mathrm{x}+0.0132, \mathrm{r} 2=$ 0.999).

Animal behavior changes due to gamma radiation

The animals treated with gamma radiation showed signs of radiation sickness within 1-2 days after exposure to 6 Gy of gamma irradiation. Reduction in food and water intake, watering eyes, weight loss, epilation, irritability, lethargy, diarrhea, ruffled hair and slow gait in animals were the main symptoms appeased after irradiation. No toxic effects were observed in terms of sickness, body weight, urination, defection pattern and mortality in animals treated with SE alone, once a day for 6 consecutive days. The mice which were pretreated with SE (experimental group) showed delay in onset of radiation-induced mortality and symptoms of sickness as compared to the control group.

Table 1 Biochemical analyses of lung glutathione in mice treated with Sambucus ebulus extract and/or gamma radiation.

\begin{tabular}{|c|c|c|}
\hline Groups & $\begin{array}{c}\text { Dose } \\
(\mathbf{m g} / \mathbf{~ k g}, \text { i.p. })\end{array}$ & $\begin{array}{c}\text { Lung } \\
\text { Glutathione } \\
(\boldsymbol{\mu m o l} / \mathbf{g})\end{array}$ \\
\hline Control & - & 22.08 \\
Irradiation(IR) & $6 \mathrm{~Gy}$ & 6.46 \\
$20 \mathrm{mg} / \mathrm{kg}$ (chronic) $+\mathrm{IR}$ & 20 & 6.70 \\
$50 \mathrm{mg} / \mathrm{kg}$ (chronic) $+\mathrm{IR}$ & 50 & 9.50 \\
$100 \mathrm{mg} / \mathrm{kg}$ (chronic) $+\mathrm{IR}$ & 100 & $13.08^{\mathrm{a}, \mathrm{c}}$ \\
$20 \mathrm{mg} / \mathrm{kg}$ (acute) $+\mathrm{IR}$ & 20 & 5.03 \\
$50 \mathrm{mg} / \mathrm{kg}$ (acute) $+\mathrm{IR}$ & 50 & $14.39^{\mathrm{b}}$ \\
$100 \mathrm{mg} / \mathrm{kg}$ (acute) $+\mathrm{IR}$ & 100 & $18.87^{\mathrm{d}}$ \\
\hline
\end{tabular}

$\mathrm{a}$ and $\mathrm{b}$ represent significance at $\mathrm{p}<0.05, \mathrm{p}<0.01$ and $\mathrm{p}<$ 0.001 levels, respectively, when compared to control or normal saline control $(10 \mathrm{ml} / \mathrm{kg}$, i.p. $)$. c and d represent significance at $\mathrm{p}<0.05, \mathrm{p}<0.01$ and $\mathrm{p}<0.001$ levels, respectively when compared to irradiation or gamma radiation treated group. 


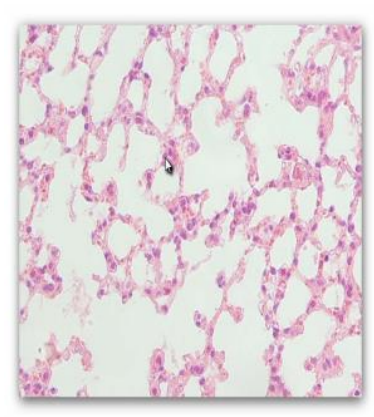

(a)

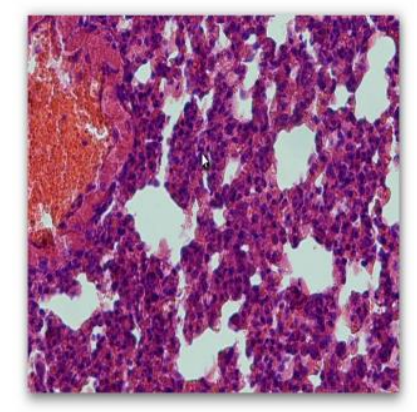

(b)

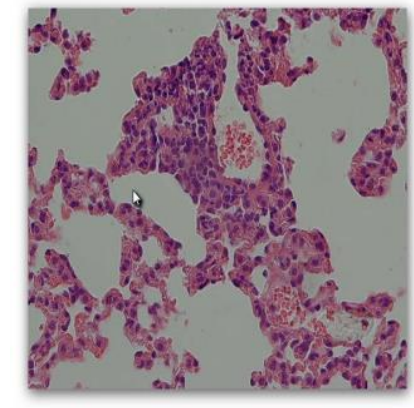

(c)

Figure 1 Photomicrograph of alveolar space from control, gamma radiation treated group and $100 \mathrm{mg} / \mathrm{kg}$ hydroalcoholic extract of Sambucus ebulus treated lung. Left is a representative section of a normal Lung (a), second, an 6 Gy gamma radiation treated group (b), third is a single dose of $100 \mathrm{mg} / \mathrm{kg}$ hydroalcoholic extract of Sambucus ebulus treated lung (c) Hematixylin and eosin (X25).

\section{Biochemical estimation}

Gamma radiation treated animals showed a significant decreasing in glutathione level in comparison to control group $(\mathrm{p}<0.001)$ (Table 1). SE showed a significant and dose dependent increase in the lung glutathione level as compared to alone gamma radiation treated group. Dose of $100 \mathrm{mg} / \mathrm{kg} \mathrm{SE}$, as the most potent dose of extract, increased the glutathione level from 6.46 (gamma radiation alone group) to $18.87 \mu \mathrm{mol} / \mathrm{g}(\mathrm{p}<0.001)$.

\section{Light microscope observation}

Histopathological examinations showed significant lung damages including necrosis and mononuclear cells infiltration in mice espoused to gamma radiation (Fig.1.b) as compared with control and extract plus irradiation groups (Fig.1.a and c).

In addition, other histopathological parameters including edematous cells and cell degeneration changed significantly with hydro alcoholic extract of SE (Table 2).

\section{Discussion}

In this study, we showed that Sambucus ebulus is containing high amounts of total phenol and flavonoids. Phenols and polyphenolic compounds, such as flavonoids, are widely found in food products derived from plant sources, and they have been shown to possess antioxidant activities. Studies have shown that increasing levels of flavonoids in the diet could decrease certain human diseases (29).
In the present study, irradiation of animals with gamma rays at dose 6 Gy resulted in radiation sickness within 1-2 days after exposure. The symptoms included reduction in food and water intake, irritability, weight loss lethargy, diarrhea and ruffling of hairs. The similar symptoms have been observed in mice after gamma irradiation by others studies (30-33). Whole-body irradiation primarily affected rapidly proliferating germinal epithelium, gastro-intestinal epithelium, renal, bone marrow and spleen progenitor cells. While the germinal epithelium did not have a life supporting function for the exposed individuals, the bone marrow, spleen progenitor cells and gastro-intestinal epithelium cells were crucial for the sustenance of life, and any damage to these cells would impair normal physiological host defense processes drastically, causing an adverse impact on survival.

Pretreatment of mice with SE provided protection against radiation-induced sickness and mitigated suffering. Similarly, plants such as Ocimumsanctum, Moringa oleifera, Mentha arvensis and Emblica officinalis have been reported to provide protection against sickness induced by radiation (34-36).

The increase in abnormal and binucleated pneumocytes indicated that the severity of the pathologic effect of radiation correlate by generating free-radicals. Free radicals are regularly formed in normal physiological as well as pathological processes and could be destroyed spontaneously due to their unstable nature. The rate of spontaneous destruction was determined by the action of certain enzymatic antioxidants such as catalase and glutathione peroxidase. 
Table 2 Histo-pathological effects of Sambucus ebulus extract at different concentrations of 20, 50, $100 \mathrm{mg} / \mathrm{kg}$ on lung mice exposed to gamma irradiation

\begin{tabular}{cccccc}
\hline Sample & Pneumocystis (hyperplasia) & Edematous cells & Hemorrhage & Necrosis \\
\hline $20 \mathrm{mg} / \mathrm{kg}$ (chronic) & $4+$ & $3+$ & $3+$ & $4+$ \\
\hline $50 \mathrm{mg} / \mathrm{kg}$ (chronic) & $4+$ & $4+$ & $3+$ & $4+$ \\
\hline $100 \mathrm{mg} / \mathrm{kg}$ (chronic) & $1+$ & $1+$ & $1+$ & $1+$ \\
\hline $20 \mathrm{mg} / \mathrm{kg}$ (acute) & $4+$ & $4+$ & $3+$ & $4+$ \\
\hline $50 \mathrm{mg} / \mathrm{kg}$ (acute) & $4+$ & $4+$ & $3+$ & $4+$ \\
\hline $100 \mathrm{mg} / \mathrm{kg}$ (acute) & $1+* *$ & $1+$ & $1+$ & $1+$ \\
\hline Control (chronic) & $1+$ & $2+$ & $1+$ & $1+$ \\
\hline Control (acute) & $1+$ & $2+$ & $3+^{*}$ & $4+*$ \\
\hline Irradiation & $4+* *$ & $4+* *$ &
\end{tabular}

No (-), Minor (+1), Medium (+2), Major (+3), high (+4), super (+5) effects, irradiation (6Gy of gamma irradiation), control $(10 \mathrm{ml} / \mathrm{kg}$ of normal saline) $* \mathrm{P}<0.05$, $* * \mathrm{P}<0.01$, significantly different from control using Fisher exact test. Data are means of three replicates.

Therefore, the net effect of free- radical injury depended upon the rate of their elimination.

In this study, we sought to determine how we could prevent or decrease the lung toxic effect of gamma irradiation. The decrease in reduced glutathione by irradiation could be due to the oxidation of the sulphydryl group of GSH due to the decrease in glutathione reductase and the enzyme which reduces the oxidized glutathione (GSSG) into a reduced form using NADPH as a source of reducing equivalent (36). Glutathione depletion has been shown to correlate with lipid peroxidation in lung parenchyma. Accordingly, when SE extract was used as antioxidant, lung toxicity effect of gamma irradiation was reduced almost about $40-50 \%$ of control.

Antioxidants, such as vitamin $\mathrm{E}$ and selenium have been proposed to prevent membrane damage of lipid peroxidation not only by glutathione peroxidase but also by allowing hydrogen to be abstracted from their own structure rather than from the allylic hydrogen of unsaturated lipid. Thus, they interrupted the free radical chain reaction (37). Treatment with SE extract has been shown to significantly decrease the toxicity of gamma irradiation. This might be through the mechanism mentioned above as well as extracts which had good reductive capability for reducing $\mathrm{Fe}^{+3}$ to $\mathrm{Fe}^{+2}$ by donating an electron

$\mathrm{Fe}^{+2}$ chelating activity and anti-lipid peroxidation activity (38). Further investigations of individual compounds to elucidate the antioxidant activities and mechanisms are needed.

Our data showed that administration of SE extract caused edema which can be assessed by histopathological examination. These findings were in agreement with the fact that an irradiation could cause increase in Oncotic pressure, or colloid osmotic pressure (39). In addition, isolated organs had a time-dependent tendency to absorb water, as with relatively protein-free medium water which gradually escaped from the vascular space and so interstitial edema developed (39). Histopathological examination revealed significant hemolysis as assessed by the hemolytic index (Fig.1.a).

This could be due to altered calcium homeostasis concomitant with a significant increase in cytosolic calcium, which has been previously reported for Phytolacca americana in liver (40). Moreover, the disturbances of intracellular calcium homeostasis have been shown to be associated with a variety of toxicological and pathological processes. Accumulation of SE extract in the lung tissue, as the target organ, has been shown to cause protection (41). In a similar 
manner, the result of this study also showed lung protection and SE extract decreased formation of reactive oxygen species and an oxidative stress resulting in lipid peroxidation and resulting in protection on lung toxicity induced by ionizing radiation $(42,43)$.

\section{Conclusion}

In this study we showed Sambucus ebulus as a natural product to have radioprotective effects against lung toxicity induced by gamma radiation. SE increased gluthathione level in

\section{References}

1. Enginar H, Cemek M, Karaca T, Unak P. Effect of grape seed extract on lipid peroxidation and peripheral blood lymphocytes in rats exposed to x-radiation. Phytoter Res 2007; 21: 1029-35.

2. Peker S, Abacioglu U, Suna I, Kony D. Prophylactic effect of magnesium and vitamin $\mathrm{E}$ in tar spinal cord radiation damage. Life Sci 2004;75:1523-30.

3. Hiermann A, Sambucus. In: Blaschek W, Ebel S, Hackenthal E, Holzgrabe U, et al, editors. Hagers Enzyklopdie der Arzneistoffe und Drogen. 14th ed. Stuttgart: Wissenschaftliche Verlagsgesellschaft $\mathrm{mbH}$, 2007.

4. Yesilada E, Ustun O, Sezik E, Takaishi Y, Ono Y, Honda G. Inhibitory effects of Turkish folk remedies on inflammatory cytokines: interleukin-1alpha, interleukinlbeta and tumor necrosis factor alpha. J Ethnopharmacol 1997; 58: 59-73.

5. Ahmadiani A, Fereidoni M, Semnanian S, Kamalinejad M, Saremi S. Antinociceptive and anti-inflammatory effects of Sambucus ebulus rhizome extract in rats. J Ethnopharmacol 1998; 61: 229-35.

6. Ebrahimzadeh MA, Mahmoudi M, Salimi E. Antiinflammatory activity of Sambucus ebulus hexane extracts. Fitoterapia 2006; 77: 146-8.

7. Yesilada E, Gurbuz I, Shibata H. Screening of Turkish anti-ulcerogenic folk remedies for anti-Helicobacter pylori activity. J Ethnopharmacol 1999; 66: 289-93.

8. Martinez, MJA, Del Olmo LMB, Benito PB. Antiviral activities of polysaccharides from natural sources. Stud Nat Prod Chem 2005;30:393-418.

9. Neto CC, Owens CW, Langfield RD, Comeau AB, Onge, JS, Vaisberg AJ, Hammond GB. Antibacterial activity of some Peruvian medicinal plants from the Callejon de Huaylas. J Ethnopharmacol 2002; 79: 1338.

10. Dawidowicz AL, Wianowska D, Baraniak B. The antioxidant properties of alcoholic extracts from Sambucus nigra L. (antioxidant properties of extracts). LWT-Food Sci Technol 2006; 39: 308-15.

11. Pieri V, Schwaiger S, Ellmerer EP, Stuppner H. Iridoid glycosides from the leaves of Sambucus ebulus. J Nat Prod 2009; 72: 1798-1803.

12. Girbes T, Citores L, Iglesias R, Ferreras JM, Munoz R, Rojo MA, et al. Ebulin 1, a nontoxic novel type 2 ribosome inactivating protein from Sambucus ebulus L. leaves. J Biol Chem 1993; 268: 18195-9.

13. De Benito FM, Citores L, Iglesias R, Ferreras JM, Soriano F, Arias J, et al. Ebulitins: a new family of type 1 ribosome-inactivating proteins (rRNA N-glycosidases) from leaves of Sambucus ebulus L. that coexist with the irradiated mice. Since, SE contains high amounts of phenol and flavonoids, which have antioxidant activity, protective effect of SE is probably due to mitigation of oxidative stress caused by gamma radiation. Future studies are needed to find the exact mechanisms related to radioprotective effect of SE.

\section{Conflict of interest statement}

The authors declared no potential conflict of interest with respect to the authorship, and/or publication of this study. type 2 ribosome-inactivating protein ebulin 1 . FEBS Lett 1995; 360: 299-302.

14. Rojo MA, Citores L, Arias FJ, Ferreras JM, Jimenez P, Girbes T. cDNA molecular cloning and seasonal accumulation of an ebulin 1-related dimeric lectin of dwarf elder (Sambucus ebulus L.) leaves. Int J Biochem Cell Biol 2003; 35: 1061-5.

15. Okuda T. Systematics and health effects of chemically distinct tannins in medicinal plants. Phytochemistry 2005; 66: 2012-31

16. Nayak SB, Sandiford S, Maxwell A. Evaluation of the wound-healing activity of ethanolic extract of Morinda citrifolia L. leaf. Evid Based Complement Alternat Med 2009; 6: 351-6.

17. Getie M, Gebre Mariam $T$, Reitz R, Neubert RH. Evaluation of the release profiles of flavonoids from topical formulations of the crude extract of the leaves of Dodonea viscosa (Sapindaceae). Pharmazie 2002; 57: 320-2.

18. Shetty S, Udupa S, Udupa L. Evaluation of antioxidant and wound healing effects of alcoholic and aqueous extract of Ocimum sanctum Linn in rats. Evid Based Complement Alternat Med 2008; 5: 95-101.

19. Tsuchiya H, Sato M, Miyazaki T, Fujiwara S, Tanigaki S, Ohyama M, et al. Comparative study on the antibacterial activity of phytochemical flavanones against methicillin-resistant Staphylococcus aureus. J Ethnopharmacol 1998; 50: 27-34.

20. Umegaki K, Sugisawa A, Shin S, Yadama K, Mitsuaki $S$. Different onsets of oxidative damage to DNA and lipids in bonmarrow and liver in rats given total body irradiation. Free Radic Biol Med 2001;3: 1066-174.

21. Etsuo N. Assessment of Antioxidant Capacity in vitro and in vivo. Free Radic Biol Med 2010;49: 503-15.

22. Ebrahimzadeh A, Bahramian F. Antioxidant activity of Crataegus pentaegyna subsp. elburensis fruits extracts used in traditional medicine in Iran. Pak J Biol Sci 2009; 12: 413-9.

23. Ebrahimzadeh MA, Nabavi SF, Nabavi SM. Antioxidant activities of methanol extract of Sambucus ebulus L. Flower. Pak J Biol Sci 2009;12:447-50.

24. Ebrahimzadeh MA, Nabavi SM, Nabavi SF, Eslami B. Antioxidant activity of aqueous extract of Pyrus boissieriana fruit. Pharmacologyonline 2009; 1: 131823.

25. Soyal A, Jindal I, Singh P, Goyal K. Protective capacity of Rosemary extract against radiation induced hepatic injury in mice. Iran. J Radiat Res 2007; 4:161-8. 
26. Goossens L. Effects of gamma-ray-induced free radicals on the metal content and amino acid composition of human metallothionein-1. J Biosci 2011; 36: 235-41.

27. Rezvani M, Ross G, Wilkinson JH. Evidence for humoral effects on the radiation response of rat foot skin. Br J Radiol 2002; 75:50-5.

28. Ellman GL. Tissue sulfhydryl groups. Arch Biochem Biophys 1959; 82:70-1.

29. Nabavi SM, Ebrahimzadeh MA, Nabavi SF, Hamidinia A, Bekhradnia AR. Determination of antioxidant activity, phenol, and flavonoid content of Parrotia persica Mey. Pharmacologyonline 2008; 2:560-7.

30. Farber JL, Kyle ME, Coleman JB. Mechanism of cell injury by activated oxygen species. Lab Invest 1990;62: 670-9.

31. Moron MS, Depierre JW, Mannervik B. Levels of GSH, GR and GST activities in rat lung and liver. Biochem Biophys 1979; 512:67-78.

32. Nemoto K, Horiuchi K, Miyamoto T. Deoxyspergualin Deoxyspergualin is a new radioprotector in mice. Radiat Res 1995; 141: 223-6.

33. Noda Y, McGeer PL, McGeer EG, Comporti M. Lipid peroxidation, biopathological Significance. Mol Aspects Med 1993; 14: 199-207.

34. Gajawat $S$, Goyal $P K$. Influence of-tocopherol (vitamin E) on hepatic lesions induced by gamma irradiation. $\mathbf{J}$ Tissue Res 2003; 3:52-6.

35. Nunia V, Goyal PK. Prevention of gamma radiation induced anemia in mice by diltiazem. Radiat Res 2004; 45: 11-7.
36. Mansour HH. Protective role of carnitine ester against radiation-induced oxidative stress in rats. Pharmacol Res 2006; 45: 165-71.

37. Hibayama SY. Role of lipid peroxidation in enhancement of endotoxin hepatotoxicity. Exp Toxicol Pathol 1992; 44: 205-8.

38. Quiles J, Ramirez M, Gonzales J. Vitamin E supplementation increases the stability and the in vivo antioxidant caoacity of refined olive oil. Free Radic Res 1999; 31:129-35.

39. Heinz TR, Kot PA, Ramwell PW, Schneidkraut MJ. Thromboxane release from irradiated perfused rat lungs: role of oncotic agents. Life Sci 1987; 41: 479-84.

40. Chen JP, Cosgriff TM. Hemorrhagic fever virusinduced changes in homeostasis and vascular biology. Blood Coagul Fibrinolysis 2000; 11: 461-83.

41. Rossini S, Benetti D, Kavetina J. The function capacity of the isolated perfused rat liver in relation to the colloidal osmotic of the perfusion medium. Farm Practice 1976; 31:625.

42. Takahashi H, Namikawa $Y$, Tanaka M, Fukuyama $Y$. Triterpene glycosides from the cultures of Phytolacca americana. Chem Pharm Bull 2001; 49: 246-8.

43. Ghanndi AR, Ghasemi-Dehkordi N. Pharmacognostical investigations on Sambucus ebulus L. and Sambucus nigra L. Daru 1997; 7:55-65. 